\title{
Detection and attribution of human influence on regional precipitation
}

Article

Accepted Version

Balan Sarojini, B., Stott, P. A. and Black, E. (2016) Detection and attribution of human influence on regional precipitation. Nature Climate Change, 6 (7). pp. 669-675. ISSN 1758-678X doi: https://doi.org/10.1038/nclimate2976 Available at https://centaur.reading.ac.uk/65605/

It is advisable to refer to the publisher's version if you intend to cite from the work. See Guidance on citing.

To link to this article DOI: http://dx.doi.org/10.1038/nclimate2976

Publisher: Nature Publishing Group

All outputs in CentAUR are protected by Intellectual Property Rights law, including copyright law. Copyright and IPR is retained by the creators or other copyright holders. Terms and conditions for use of this material are defined in the End User Agreement.

\section{www.reading.ac.uk/centaur}

\section{CentAUR}

Central Archive at the University of Reading

Reading's research outputs online 


\section{Detection and Attribution of Human Influence on 2 Regional Precipitation}

4 Beena Balan Sarojini ${ }^{1,2,3^{*}}$, Peter A. Stott ${ }^{4}$ and Emily Black ${ }^{1,2}$

5

$6 \quad{ }^{1}$ National Centre for Atmospheric Science - Climate Directorate, Reading, UK

$7 \quad{ }^{2}$ Department of Meteorology/Walker Institute, University of Reading, UK

$8{ }^{3}$ Department of Geography and Environmental Science, University of Reading, UK

$9 \quad{ }^{4}$ Met Office Hadley Centre, Exeter, UK

10

11

12

13

14

15

16

17

18

19

20

21

22

23

24

25

26

27

28

29

30

31

32

33

34

35

36

37

\section{February 2016}

(Revised)

*Corresponding author: Beena Balan Sarojini (b.balansarojini@reading.ac.uk)

NCAS - Climate, Department of Meteorology

University of Reading, Reading RG6 6BB, United Kingdom

Phone: + 44118378 6238, Fax: + 441183788316 
38 Understanding how human influence on climate is affecting precipitation around the

39 world is immensely important for defining mitigation policies, and for adaptation

40 planning. Yet despite increasing evidence for the influence of climate change on

41 global patterns of precipitation, and expectations that significant changes in regional

42 precipitation should have already occurred as a result of human influence on climate,

43 compelling evidence of anthropogenic fingerprints on regional precipitation is

44 obscured by observational and modelling uncertainties and is likely to remain so using

45 current methods for years to come. This is in spite of substantial ongoing

46 improvements in models, new reanalyses and a satellite record that spans over thirty

47 years. If we are to quantify how human-induced climate change is affecting the

48 regional water cycle, we need to consider novel ways of identifying the effects of 49 natural and anthropogenic influences on precipitation that take full advantage of our 50 physical expectations.

52 How rainfall is changing in a particular region is a question of great practical

53 importance to societies. Floods and droughts threaten the lives and livelihoods of 54 many people and enhancing their resilience is of major concern, particularly as 55 anthropogenic climate change is expected to increase the frequency of floods and 56 droughts ${ }^{1}$. These expected changes may, moreover, render risk assessments based 57 purely on the historical record inaccurate. Well-planned adaptation to climate change 58 thus requires information on how hazardous rainfall is changing in response to 59 anthropogenic forcing. Are we observing systematic changes or are we simply 60 experiencing natural variability? This is the business of detection and attribution (Box $611)$ 
62 New observations and improved models have enabled the detection of anthropogenic

63 change in the water cycle at large spatial scales ${ }^{2,3,4}$, although even here large 64 uncertainties remain. The Intergovernmental Panel on Climate Change ${ }^{5}$ (IPCC) in its 65 Fifth Assessment Report (AR5) concludes that it is likely that anthropogenic 66 influences have affected the global water cycle since 1960. In Section TS. 6.3 of AR5, 67 two key uncertainties which limit confidence in attribution assessments of the causes of precipitation changes are recognised as 1) observational and modelling uncertainties, and 2) the large effect of internal variability. Hence there is only medium confidence that there is an anthropogenic contribution to global-scale changes 71 in precipitation patterns over land since 1950, with higher levels of confidence 72 precluded by uncertainty in models and observations and the large internal variability 73 in precipitation ${ }^{6}$.

74 At continental scales, there has been some limited success in detecting anthropogenic 75 changes in land precipitation. Anthropogenically driven changes in zonal averages of 76 land precipitation were detected by e.g., ref. 7 - although in some cases the results 77 were found to be sensitive to the observational dataset used. Anthropogenic trends in 78 precipitation have also been detected in the northern mid-to-high latitude lands ${ }^{8,9}$ and 79 southwest Australia ${ }^{10}$, where in both regions there are large expected trends that are 80 coherent over wide areas (Figure TS.16 of IPCC, 2013). In general, however, 81 detection and attribution of an anthropogenic signal at these scales is hampered by 82 observational uncertainty and model error $^{2,6,8,9,11}$. Even the continental-scale studies 83 described above are too coarse to inform assessments of the extent to which human84 induced climate change has affected changes affecting many people locally. Because 85 internal variability in precipitation tends to increase with reducing spatial scale there may be a tendency to assume that detection of an anthropogenic signal of change is 
more likely at global or continental scales than at regional scales. In this context, by regional scales we refer to smaller spatial scales than 'continental', typically thinking of areas of the globe characterised by specific geographic and climatological

90 features ${ }^{5}$.

91 This perspective argues that analysis of changes in the processes governing internal 92 variability in precipitation should facilitate the detection and attribution of 93 anthropogenic changes at a range of spatial scales. In some cases an anthropogenic 94 signal may be easier to detect at regional scales, where we have a clearer expectation 95 of forced changes ${ }^{8,9,10}$. Above all progress in detection and attribution of changes in 96 the water cycle requires the development of novel metrics, which should help 97 facilitate the identification of significant changes in precipitation even in the presence 98 of substantial modelling and observational uncertainty ${ }^{12}$. This should enable faster 99 progress to be made than would be possible by simply waiting for models or 100 observations to improve or by simply waiting for the signal of climate change to 101 strengthen sufficiently to emerge from the noise of internal variability.

102 We first compare physical expectations of global and regional anthropogenic changes 103 in precipitation. Next, we describe how spatial scale modifies the impact of model 104 error and observational uncertainty on detection of these changes. We then consider 105 how novel methods of analysis can be brought to bear on detection and attribution of 106 regional changes in precipitation. Finally, we reflect on how our current models and 107 observations can best be utilised to provide a robust view of anthropogenic change in 108 regional precipitation. 
110 Based on the physical relation of Clausius-Clapeyron, surface warming is expected to

111 result in an increase in water vapour concentrations at a rate of 6-7\% per Kelvin ${ }^{13}$, 112 given that the relative humidity is expected to remain nearly constant ${ }^{14}$. This 113 thermodynamic expectation of an intensification of the water cycle has been 114 confirmed in changes in observed and simulated atmospheric moisture content over 115 land and ocean ${ }^{15,16,17,18}$, albeit in observations from recent years there is some 116 evidence of a reduction of relative humidity over land ${ }^{19}$.

117 Global mean precipitation is not, however, expected to scale with the increase in 118 atmospheric moisture because it is controlled not by specific humidity, but by the 119 energy budget of the troposphere. The two complementary energy budget arguments 120 are 1) the tropospheric latent heating during precipitation formation is balanced by the 121 radiative cooling to outer space ${ }^{14}$, and 2) at the surface the latent heat flux (which is 122 proportional to global mean evaporation and hence global mean precipitation) is 123 balanced by the sensible and radiative heat fluxes ${ }^{14,13,15,20}$. The warming of the 124 troposphere increases the radiative cooling rate and hence the precipitation. However, 125 if the warming is driven by an increase in greenhouse gases (GHGs), the increase in 126 the radiative cooling rate is partly offset by the direct radiative effect of the GHGs, 127 which is to decrease the radiative cooling rate. This implies that the precipitation 128 response to GHG forcings is smaller per unit change in forcing, than it is for short 129 wave radiative forcings like volcanic aerosol ${ }^{14}$. Overall anthropogenic forcings result 130 in a lower rate of increase in precipitation globally than suggested by the Clausius131 Clapeyron relation ${ }^{14,13,15,20,21,22}$.

132 A pioneering study $^{14}$ quantified the expected range of change in total global 133 precipitation in response to $\mathrm{CO}_{2}$ driven warming, but found that even at large scales 134 there was considerable variation in the expected spatial pattern of change. A key 
135 advance in the physical explanation of the response pattern of precipitation changes

136 due to increasing GHGs was made by a later study ${ }^{15}$. They identified robust features

137 of anthropogenic changes such as enhancement of the patterns of precipitation minus

138 evaporation (P-E), poleward movement of the Hadley circulation and subsequent

139 shifting of the arid subtropical subsidence regions and storm tracks, leading to the

140 'wet gets wetter' and 'dry gets drier' paradigm. It has recently been found that

141 although this paradigm has some validity over wet higher latitudes and dry subtropical

142 land regions, it does not hold true everywhere. For example, humid to transitional

143 regimes are shifting to drier conditions ${ }^{23}$. Other changes in large-scale rainfall patterns

144 have been explained through a 'warmer-get-wetter' mechanism, by which warm SST

145 patterns over the tropics cause increases in precipitation ${ }^{24}$.

\section{Expectation of regional changes}

147 Change in regional rainfall is a consequence both of thermodynamics and

148 anthropogenic influence on dynamics ${ }^{25}$. Human-induced depletion in stratospheric 149 ozone, for example, is found to cause a poleward shift of the southern extratropical 150 jets, which affect regional precipitation patterns in the Southern Hemisphere ${ }^{26,27}$. The 151 storm track in the Northern Hemisphere, and hence rainfall in Europe, are also 152 affected by changes in stratospheric circulation ${ }^{28}$.

153 More generally, the regional precipitation response to naturally occurring modes of 154 variability, such as ENSO and the NAO, is influenced by the basic state of the 155 atmosphere and ocean ${ }^{14,29,30}$. It is to be expected therefore that anthropogenic 156 perturbations to the basic state would lead to changes in regional teleconnection 157 patterns. 
The regional character of anthropogenic precipitation change, therefore, results from complex interactions between natural variability and anthropogenic forcing. This is

160 especially the case at regional scales. Indeed, variability related to teleconnections is 161 not likely to affect total precipitation over very large domains, because wetter 162 conditions in one place tend to be balanced by dryer conditions elsewhere ${ }^{31}$. In short, 163 in order to disentangle the complex causes of regional precipitation change, we need 164 to consider the following three aspects of the response: 1) external forcing may 165 project onto internal variability, changing the amplitude or frequency of modes of 166 climate variability, or altering the teleconnections that govern precipitation response, 167 2) the fingerprint of external forcing may reflect both thermodynamic and dynamic 168 changes through forced changes to atmospheric energetics, moisture content, and 169 large-scale circulation, and 3) the precipitation responses to different external drivers 170 such as greenhouse gases, aerosols, ozone, natural events will differ.

\section{$171 \quad$ Modelling and observational uncertainties}

172 Recent studies that have sought to detect and attribute anthropogenic signals in large173 scale zonal precipitation have compared observations to CMIP5 (Coupled Model 174 Intercomparison Project 5) model simulations with and without anthropogenic 175 forcings ${ }^{2,3}$. Anthropogenic increases in precipitation on global land and ocean are 176 clear in model simulations (Figure 1a-c). However attribution approaches require that 177 like is compared with like by comparing observations of the historical period to 178 models that have been masked with the observational coverage. This means that the 179 clear signals seen in models are obscured by sparse observational coverage ${ }^{2}$. These 180 findings indicate that global as well as zonal trends are distorted by the aliasing of 181 sparse observational coverage onto the multi-model means. 
182 The robustness of the detection of global and large-scale trends (Figures 10.10 \& 183 10.A.2 of ref. 6) needs to be tested by comparing model data with different datasets of 184 long-term observations. Ref. 2, for example, detected seasonal changes in zonal-mean 185 precipitation attributable to human activities in four observational datasets - albeit 186 only for March-April-May and December-January-February. However, the 187 magnitudes of the temporal fingerprint of mid-to-high latitude positive trends and low 188 latitude negative trends vary between observational datasets (Figure 2). In fact, 189 anthropogenic changes are detected for all seasons in only one of the observational 190 datasets $^{3}$. The sensitivity of findings to observational dataset illustrates the barriers 191 imposed by observational uncertainty.

192 The above discussion has focussed on uncertainties in observations of precipitation. 193 It should not be forgotten, however, that effective model-observation comparison 194 relies on accurate observations, not only of the variable in question, but also of 195 forcing factors, including natural and anthropogenic aerosol. It has been found, for 196 example, that natural desert dust aerosols from North Africa and West Asia are 197 positively correlated to Indian summer monsoon rainfall on short time scales, with the 198 dust-induced heating favouring increased moisture convergence over the Arabian 199 peninsula and hence the westerly flow and precipitation over the Indian 200 subcontinent ${ }^{32}$. Such model based findings point to the increasing need for an 201 improved understanding of the climatic response to aerosols, which will require more 202 systematic modelling experiments exploring the sensitivity of the precipitation 203 response to aerosol forcing uncertainty as well as improvements in the representation 204 of aerosol forcing in models.

205 Many of the impacts of a changing water cycle are felt at regional and local scales 206 rather than at continental or global scales. Observational uncertainty at any given grid 
207 point (of resolution of a few hundreds of $\mathrm{kms}$ ) may be greatest at these scales 208 (http://sciforum.net/conference/66/paper/2901). Paradoxically, however, 209 observational uncertainty may be less of a barrier to attribution at the regional than at 210 the global level. At the largest spatial scales, many of the detection and attribution

211 issues related to observational uncertainty stem from sparse spatial sampling ${ }^{2}$ in 212 observations which means that the trends from models and observations can be badly 213 distorted, losing much of the underlying signals. At local scales, in contrast, 214 inconsistency in spatial sampling is less likely to contribute significantly to 215 observational uncertainty. Instead, observational uncertainty reflects the sparcity of 216 ground observations and consequent measurement/calibration errors. Such uncertainty 217 may not, in itself, preclude robust detection and attribution of anthropogenic change 218 in some regions, providing there exist temporally consistent ground or satellite based 219 rainfall estimates. Indeed, at these scales, detection and attribution may be hampered 220 more by the challenge of comparing models and observations, than by observational 221 uncertainty itself. This is, in part because there are large discrepancies between the 222 locations of simulated and observed features in the climatologies of precipitation 223 which might be expected to cause differences in the anthropogenic response ${ }^{33}$. These 224 discrepancies are compounded by the lack of robustness in model-simulated internal 225 variability $^{34}$ causing uncertainty in the fingerprint ${ }^{3,35}$, or under sampling of the 226 observed variability ${ }^{36}$ - which as described in earlier sections are a particularly serious 227 issue at the regional scale.

\section{A clearer view}

229 The success of any approach to detection and attribution is contingent on the model's 230 ability to represent the relevant processes over a particular region and season. 231 Structural uncertainties in climate models (due to the differences in models' structure 
232 leading to individual model errors), although reduced since the Fourth Assessment 233 Report $^{37,38}$ (AR4), remain as a barrier to quantifying robust change in precipitation on 234 regional scales ${ }^{39}$.

235 The need for improved process-representation has motivated recent work on improved 236 model dynamics and resolution ${ }^{40}$, and the incorporation of individual processes and 237 complex models of individual parts of the climate system ${ }^{41}$. High horizontal and 238 vertical resolution and improved parameterisations in climate models have been 239 shown to improve representation in models of processes, such as the vorticity of 240 tropical cyclones, storm dynamics, atmospheric fronts, convection and blocking,

241 clouds and their interactions with aerosols, gravity waves, ocean-biogeochemistry, 242 land and sea-ice, boundary layer and land-surface processes, and strength of the local 243 hydrological cycle ${ }^{40,41,42,43,44,45}$. The development of both high-resolution climate 244 models and Earth System Models (ESMs) are thus instrumental in tackling regional 245 climate problems. Ref. 40, for example, performed climate change experiments using 246 a $1.5 \mathrm{~km}$ resolution regional climate model and projected future increase in heavy 247 downpours over the UK. They illustrated that explicit convection and local storm 248 dynamics are important in simulating the fine temporal and spatial scales of UK 249 summer rainfall.

250 Compared to CMIP3 models, many CMIP5 models represent first and second indirect 251 effect of aerosols and improved aerosol-cloud representations. On large spatial 252 scales, these significant improvements in climate model representation of aerosols 253 have now enabled improved simulation of inter-decadal variability in temperature and 254 precipitation $^{35,46}$. A weakening of the Northern Hemisphere land precipitation 255 between the 1950s and 1980s and a subsequent recovery has been detected and 256 attributed to increasing anthropogenic aerosols during 1950 to 1980 s followed by a re- 
emergence of the greenhouse gas signal relative to the anthropogenic aerosol signal in later years ${ }^{35}$. Models with representation of the indirect effect of sulphate aerosols, together with the direct effect of sulphate aerosols perform better in representing the 260 rate of decrease of precipitation in the 1950s and the recovery in the 1980 s than the 261 models that exclude the indirect effect $^{46}$ although models still have shortcomings in 262 representing the timing of the recovery. There is thus a scientific opportunity to use 263 these newly available simulations to decipher the joint influence of anthropogenic 264 aerosols and greenhouse gas emissions on regional precipitation, and hence to detect 265 anthropogenic trends.

\section{New methodologies}

267 The base climate is expected to vary from one model to another. Averaging 268 simplistically over output from many models may therefore obscure signals of 269 anthropogenic change. For instance, variation between models of the location and 270 seasonal timing of precipitation may hamper robust assessment of changes in the 271 mean $^{33,47,48}$. Novel methods of accounting for the mismatches between model 272 climatologies offer a means of tackling the problem of consistent model changes 273 being distorted by differences in climatological features (eg. convergence zones) both 274 between models, and between models and observations ${ }^{33,49}$. In order to correct feature

275 location errors in GCMs, ref. 33 applied a warping method, which has been used in 276 brain imagery registration, to monthly precipitation fields. The warping technique was 277 found to improve the detectability of human influence ${ }^{49}$. Other model-observation 278 comparison methods such as the model-by-model approach $^{48}$ and space-scale 279 smoothing ${ }^{47}$, which consider individual model runs as opposed to the multi-model 280 ensemble mean, have also been shown to reduce feature-location biases and hence to 281 identify robust changes in the location and magnitude of zonal extremes. 
Natural variability, as well as systematic bias in models, can obscure part of the signal

283 of anthropogenic change in precipitation. For example, the anthropogenic effect on

284 the precipitation response to natural modes of variability is superposed on natural

285 variation in the amplitude and frequency of these modes ${ }^{50,51,52,53}$. Aliasing natural

286 internal variability and changes due to anthropogenic forcing in this manner would be

287 expected to cause variations in the anthropogenic effect on regional precipitation. So

288 if, say, greenhouse gas forcing modifies the precipitation response to ENSO in a given

289 region, the anthropogenic expression of precipitation change is more pronounced

290 during periods when ENSO is active. These periods cannot be expected to coincide

291 in free-running coupled climate models. Averaging precipitation over large model

292 ensembles will therefore not reveal this component of the signal of anthropogenic

293 influence. Rather detection and attribution tecnhniques need to take explicit account

294 of the drivers of precipitation variability (e.g. ENSO, NAO) and to their effects on

295 precipitation (e.g. ENSO teleconnections) rather than just treating such variability as

296 noise in the analysis. This type of process-based approach complements the

297 application of detection and attribution techniques directly to regional precipitation ${ }^{8,9}$

298 and can yield a clearer understanding of the role of natural and anthropogenic 299 factors $^{71}$.

300 On regional scales, therefore, in addition to analysing precipitation directly, it is 301 productive to investigate the processes underlying precipitation change (process-based 302 fingerprints). Examples of such fingerprints are the increased risk of heavy rainfall 303 during mid-latitude atmospheric river events in the $\mathrm{UK}^{54,55}$ and New Zealand ${ }^{56}$; the 304 poleward migration of the storm $\operatorname{track}^{47}$ (Figure 3) and the large scale dynamical 305 implications of an expected intensification of the hydrological cycle $e^{15,20,57,58}$ that, at least over non-water limited regions ${ }^{23}$ of the earth including the oceans, many wet 
regions tend to get wetter and dry regions drier. As pointed out earlier it should be noted that the over simplicity of this expectation from theory and models is currently under discussion ${ }^{23}$. However, a temporal response pattern with wet tropical regions getting wetter and dry regions getting drier was apparent in simulations of the recent

311 past and future projections from CMIP5 models and was consistent with satellite rainfall observations for the tropical region ${ }^{20}$. ENSO variability can cause increase or decrease of regional rainfall over the land depending on the sign of the phase ${ }^{58}$

314 suggesting if the ENSO characteristics change such precipitation response which is 315 governed by remote SST patterns may change too. On fine scales, shifting of the wet 316 and dry regions may make it difficult to identify this expected pattern of change $\mathrm{e}^{23 \text {, }}$ $317{ }^{59,60}$. However, using two fingerprints of wet and dry processes, ref. 57 detected an 318 expected intensification of the water cycle partly attributable to human-induced 319 greenhouse gas forcing.

320 Anthropogenic change in precipitation is driven not only by greenhouse gas emission,

321 but also by aerosol forcing which modulates regional precipitation. Sulphate aerosol 322 and desert dust forcings influence changes in the wet and dry conditions of Sahelian 323 water cycle caused primarily by changes in West African Monsoon rains through 324 changes in SST feedbacks and subsequent shifts in tropical convergence zones ${ }^{61,62}$. 325 Simulated Sahel rainfall is found to weaken due to rapid changes in anthropogenic 326 sulphur dioxide emissions from Asia and Europe through a fast (less than 3 weeks) 327 aerosol-radiation and aerosol-cloud response and a slow (more than 3 weeks) 328 response (i.e. decrease in West African Monsoon by adjustment of Walker 329 circulation) caused by atmosphere and land-surface feedbacks ${ }^{63}$. While there was a 330 decrease of Sahel rainfall during the 1970s and 1980s since then there has been some recovery of Sahel rainfall which could have been influenced by increasing levels of 
332

333

greenhouse gases in the atmosphere as well as changes in anthropogenic aerosol precursor emissions ${ }^{64}$.

\section{Event attribution}

The previous discussion has highlighted the importance of identifying and isolating processes underlying anthropogenic change in precipitation. This can be accomplished, as described in the studies cited above, by explicitly isolating candidate processes and investigating how they are affected by anthropogenic climate change. A further refinement is to investigate the anthropogenic contribution to the processes underpinning individual extreme events - a technique known as event attribution.

Event attribution studies seek to determine how anthropogenic forcings have altered the magnitude or probability of a particular type of extreme weather or climate-related event as experienced in the observed record ${ }^{65,66,67}$. In recent years efforts have been made to carry out such studies shortly after the events in question, for example in the publication of an annual series of reports which explain extreme events of the previous year from a climate perspective ${ }^{68}$. However while there is increasing evidence that robust attribution statements can be made about an anthropogenic contribution to the likelihood of many extreme warm events, the role of human influences on extreme precipitation events is decidedly mixed ${ }^{69}$ consistent with previous findings about the difficulties of robustly attributing precipitation events. Nevertheless such diagnostic approaches to attribution have made some headway in breaking down the problem into thermodynamic and dynamical components ${ }^{70}$ and in devising modelling strategies to quantify the different contributions from anthropogenic and natural forcings and aspects of internal variability ${ }^{64}$. It is therefore 
356 extreme precipitation event through developing an understanding of the

357 thermodynamic and dynamic contributors ${ }^{71,72}$. Ref. 73 argues that in attributing 358 extreme climate events it is more useful to regard the extreme circulation regime or 359 weather event as being largely unaffected by climate change and to concentrate solely 360 on the thermodynamic component of an anthropogenic impact on the event in 361 question. However it is important to consider dynamic factors as well as 362 thermodynamic factors and to consider the extent to which dynamical aspects may 363 have changed since it is both that contribute to the risk of a particular event ${ }^{74,71,72,75}$. 364 Also attention should be given as to whether there are non-linear interactions between 365 the two, as discussed above.

\section{The way ahead}

367 Based on our discussion of scientific opportunities and challenges, we emphasise that 368 quantification of the effects of human influence on precipitation across the globe 369 crucially depends on developing and applying process understanding. Given current 370 observational uncertainties ${ }^{4}$ and limitations in models ${ }^{38}$ simply waiting for 371 improvements in observations and models to deliver clearer detection and attribution 372 results seems an insufficient response to the challenge of better understanding how 373 climate change is affecting precipitation around the globe. For example some of the 374 important recommendations proposed by ref. 4 such as the observational data rescue, 375 improvements in the observational coverage and models could take years to 376 implement. Clearly observations and models are continuously improving and 377 detection and attribution analyses should take advantage of such advances. But 378 adaptation decisions could be even better informed if it were possible to incorporate 379 process understanding more in detection and attribution studies. Those adaptation 380 decisions that are based on robust climate projections are much stronger where the 
381 projections are based on firm foundation of physical understanding and underpinned 382 by robust attribution studies. Hence attribution studies are central to informed 383 adaptation planning and decision making. Even where large uncertainties remain, 384 additional useful information could be obtained and applied in a risk-based 385 framework ${ }^{60}$ based on an understanding of the likely mechanisms at work.

386 In particular, we need to better understand the expected effect of anthropogenic 387 climate change on modes of variability and their teleconnections with regional 388 precipitation ${ }^{29}$. Disentangling these effects will allow an improved understanding of 389 the extent to which regional changes are anthropogenically caused versus being 390 caused by natural variations, either internally generated within the climate system or 391 externally forced, such as by solar variability or explosive volcanic eruptions. It is not 392 always reasonable to consider internal variability simply as 'noise' to be filtered out.

393 Recent process-based detection and attribution approaches ${ }^{47}$, which consider the 394 signal or the forced response being thermodynamic and/or dynamic in origin, have 395 shown some success. There is indication that the anthropogenic signal could also be 396 expressed in part through changes in amplitude, frequency and modes of natural 397 internal variability. An alternative approach would be to look directly at the 398 anthropogenic signal as a net effect of rainfall changes due to a) thermodynamic 399 contribution, b) dynamic contribution (which includes changes in circulation, modes 400 of variability and changes in teleconnections due to changes in modes of variability). 401 Analyses quantifying changes in natural internal variability ${ }^{76}$ would be a valuable 402 addition to quantifying forced changes over regions where internal variability on 403 interannual timescales is changing. However, it is very difficult to robustly detect 404 changes in observed variability for a highly noisy climate variable as precipitation. 
405 New metrics that best express robust changes in the water cycle would aid in 406 identifying anthropogenic changes. For example this could involve calculating areas 407 of land with precipitation changes at particular thresholds ${ }^{12}$ or could involve 408 combining terrestrial observations of precipitation with oceanographic observations of 409 salinity $^{6}$.

410 In summary, we have shown that, even in the face of imperfect models and

411 observations, progress can be made in detecting and attributing changes in regional 412 precipitation. Improved process understanding, innovations in detection and 413 attribution methodologies, and novel methods of confronting models with 414 observations can now be brought to bear on this highly challenging problem.

415 Development of high quality observational datasets and high-resolution models will

416 be undoubtedly helpful and are likely to have substantial pay off over the longer term.

417 But in the meantime, innovative methods for analysing the observations and models 418 we have available now could yield important additional information to inform 419 societies and policy makers about the nature of changing precipitation at fine spatial420 scales.

\section{Box 1. What is detection and attribution?}

423 Detection of a change is the process of demonstrating that climate has changed in 424 some defined statistical sense, without providing a reason for that change ${ }^{77}$. 425 Attribution of causes of the change is defined as the process of evaluating the relative 426 contributions of multiple causal factors to a change or event with an assignment of 427 statistical confidence ${ }^{6}$. Fingerprints are metrics or space-time patterns of the response 428 of climate variables to anthropogenic forcings, such as greenhouse gas emissions, 429 atmospheric pollutants, or natural forcings such as solar radiation changes and 
aerosols from explosive volcanic eruptions. Most of the recent detection and

431 attribution studies use climate models $^{78}$ to estimate the expected fingerprints of

432 change and the uncertainty of their estimate in observations of the real world. For an

433 overview of techniques, see Appendix 9.2 of AR4 ${ }^{62}$ and Section 10.2.1 of AR5 $5^{6}$.

References:

1. IPCC, Summary for Policymakers. In: Climate Change 2014: Impacts, Adaptation, and Vulnerability. Part A: Global and Sectoral Aspects. Contribution of Working Group II to the Fifth Assessment Report of the Intergovernmental Panel on Climate Change (eds Field, C. B. et al.). Cambridge University Press. 1-

2. Balan Sarojini, B., Stott, P.A., Black, E. \& Polson, D. Fingerprints of changes in annual and seasonal precipitation from CMIP5 models over land and ocean. Geophys. Res. Lett. 39, L21706, DOI: 10.1029/2012GL053373 (2012).

3. Polson, D., Hegerl, G.C., Zhang, X. \& Osborn, T. Changes in seasonal land precipitation during the latter twentieth-century. J. Clim. 20, 6679-6697 (2013a).

4. Hegerl, G.C. et al. Challenges in quantifying changes in the global watercycle. Bull. Am. Meteorol. Soc. DOI:10.1175/bams-d-13-00212.1 (2015).

5. IPCC, Climate Change 2013: The Physical Science Basis. Contribution of Working Group I to the Fifth Assessment Report of the Intergovernmental Panel on Climate Change (eds Stocker, T.F., et al.). Cambridge University Press (2013).

6. Bindoff, N.L. et al. Detection and Attribution of Climate Change: from Global to Regional. In: Climate Change 2013: The Physical Science Basis. Contribution of Working Group I to the Fifth Assessment Report of the Intergovernmental Panel 

952 (2013).

7. Noake, K., Polson, D., Hegerl, G. \& Zhang, X. Changes in seasonal land precipitation during the latter twentieth-century. Geophys. Res. Lett. 39, L03706 (2012).

8. Min, S., Zhang, X. \& Zwiers, F.W. Human-induced Arctic moistening. Science 320, 518-520 (2008).

9. Wan, $\mathrm{H}$, et al. Attributing northern high-latitude precipitation change over the period 1966-2005 to human influence. Clim. Dyn, DOI: 10.1007/s00382-0142423-y (2014).

464 10. Delworth, T.L. \& Zeng, F. Regional rainfall decline in Australia attributed to 465 anthropogenic greenhouse gases and ozone levels. Nature Geosci. 7, 583-587, DOI: 10.1038/ngeo2201 (2014).

467 11. Zhang, X, et al. Detection of human influence on twentieth-century precipitation trends. Nature 448, 461-465 (2007).

469 12. Chadwick, R., Good P., Martin G. \& Rowell D.P. Large rainfall changes 470 consistently projected over substantial areas of tropical land. Nature Clim. Change. 5, 1-5 (2015).

13. Trenberth, K.E. Changes in precipitation with climate change. Clim. Res. 47, 123138 (2011).

474 14. Allen, M.R., \& Ingram, W.J. Constraints on future changes in climate and the 475 hydrologic cycle. Nature 419, 224-232, DOI: 10.1038/nature01092 (2002).

476 15. Held, I.M., \& Soden, B.J. Robust responses of the hydrological cycle to global warming. J. Clim., 19, 5686-5699 (2006). 
16. Willett, K.M., Jones, P.D., Gillett, N.P. \& Thorne, P.W. Attribution of observed surface humidity changes to human influence. Nature 449, 710-713, DOI:10.1038/nature06207 (2007).

17. Santer, B.D. et al. Identification of human-induced changes in atmospheric moisture content. Proc. Natl. Acad. Sci. 104, 15248-15253 (2007).

18. Santer, B.D. et al. Incorporating model quality information in climate change detection and attribution studies. Proc. Natl. Acad. Sci. 106, 14778-14783 (2009).

19. Blunden, J., and Arndt, D.S. Eds., State of the Climate in 2013. Bull. Amer. Meteor. Soc. 95, 1-238 (2014).

20. Allan, R.P. et al. Physically consistent responses of the global atmospheric hydrological cycle in models and observations. Surv. Geophys. DOI: 10.1007/s10712-012-9213-z (2013).

21. Pendergrass, A.G. \& Hartmann, D.L. The atmospheric energy constraint on global-mean precipitation change. J. Clim., 27, 757-768 (2014).

22. Thorpe, L. \& Andrews, T. The physical drivers of historical and $21^{\text {st }}$ century global precipitation changes. Environ. Res. Lett. 09, 064024 (2014).

23. Greve, P. et al. Nature Geosci. 7, 716-721 (2014).

24. Xie, S.-P. et al. Global warming pattern formation: Sea surface temperature and rainfall. J. Clim., 23, 966-986 (2010).

25. Seager, R.J. Thermodynamic and dynamic mechanisms for large-scale changes in the hydrological cycle in response to global warming. J. Clim., 23,4651-4668 (2010).

26. Kang, S.M., Polvani, L.M., Fyfe, J.C. \& Sigmond, M. Impact of polar ozone depletion on subtropical precipitation. Science 332, 951-954 (2011). 
27. Min, S.-K., \& Son, S.-W., Multimodel attribution of the Southern Hemisphere Hadley cell widening: Major role of ozone depletion, J. Geophys. Res. Atmos., 118, 3007-3015, DOI:10.1002/jgrd.50232 (2013).

28. Scaife, A. et al. Climate change projections and stratosphere-troposphere interaction, Clim. Dyn. 38, 2089-2097 (2012).

29. Seager, R.J., Naik, N \& Vogel, L. Does Global Warming Cause Intensified Interannual Hydroclimate Variability? J. Clim., 25, 3355-3372 (2012).

30. Vecchi, G.A., \& Wittenberg, A.T., El Niño and our future climate: where do we stand? Wiley Interdisciplinary Reviews: Climate Change 1.2, 260-270 (2010).

31. Nicholson, S.E., \& Kim, J. The relationship of the El Nino-Southern oscillation to African rainfall. International Jn. of Clim. 17.2, 117-135 (1997).

32. Vinoj, V. et al. Short-term modulation of Indian summer monsoon rainfall by West Asian dust. Nature Geosci. 7, DOI: 10.1038/ngeo2107 (2014).

33. Levy, A.A.L. et al. Can correcting feature location in simulated mean climate improve agreement on projected changes? Geophys. Res. Lett. 40, DOI: 10.1029/2012GL053964 (2013).

34. Collins, M. et al. Observational challenges in evaluating climate models. Nature Clim. Change 3, 940-941 (2013).

35. Wu, P., Christidis, N. \& Stott, P.A. Anthropogenic impact on Earth's hydrological cycle. Nature Clim. Change DOI: 10.1038/NCLIMATE1932 (2013).

36. Wan, H. et al, Effect of data coverage on the estimation of mean and variability of precipitation at global and regional scales, J. Geophys. Res. Atmos., 118, 534-546, DOI:10.1002/jgrd.50118 (2013). 
525 37. Flato, G. et al. Evaluation of Climate Models. In: Climate Change 2013: The 526 Physical Science Basis. Contribution of Working Group I to the Fifth Assessment 527 Report of the Intergovernmental Panel on Climate Change [eds Stocker, T.F. et 528 al.]. Cambridge University Press. (2013).

529 38. Stevens, B. \& Bony, S. What are climate models missing? Science 340, 1053$530 \quad 1054(2013)$.

531 39. Knutti, R. \& Sedlacek, J. Robustness and uncertainties in the new CMIP5 climate 532 model projections. Nature Clim. Change 3, 369-373 (2013).

533 40. Kendon, E.J. et al. Heavier summer downpours with climate change revealed by 534 weather forecast resolution model. Nature Clim. Change 4, 570-576, DOI: $10.1038 /$ nclimate2258 (2014).

41. Cox, P.M. et al. Sensitivity of tropical carbon to climate change constrained by carbon dioxide variability. Nature 494, 341-344, DOI: 10.1038/nature11882 (2013).

42. Roberts, M.J. et al. Tropical cyclones in the UPSCALE ensemble of high resolution global climate models. J. Clim., 28, 574-596. ISSN 1520-0442 DOI: 10.1175/JCLI-D-14-00131.1 (2015).

43. Demory, M.-E. et al. The role of horizontal resolution in simulating drivers of the 543 global hydrological cycle. Clim. Dyn., 42, 2201-2225. ISSN 0930-7575 DOI: $10.1007 / \mathrm{s} 00382-013-1924-4$ (2013).

545 44. Jung, T., et al. High-Resolution Global Climate Simulations with the ECMWF 546 Model in Project Athena: Experimental Design, Model Climate, and Seasonal 547 Forecast Skill. J. Clim., 25, 3155-3172. DOI:10.1175/JCLI-D-11-00265.1 (2012). 
45. Strachan, J., Vidale, P.L., Hodges, K., Roberts, M. and Demory, M.E. Investigating global tropical cyclone activity with a hierarchy of AGCMs: the role of model resolution. $J$. Clim., 26, 133-152. ISSN 1520-0442 DOI: 10.1175/JCLI-D-12-00012.1 (2013).

46. Wilcox, L.J., Highwood, E.J. \& Dunstone, N.J. The influence of anthropogenic aerosol on multi-decadal variations of historical global climate. Environ. Res. Lett. 8 (2). 024033. ISSN 1748-9326 DOI: 10.1088/1748-9326/8/2/024033 (2013).

47. Marvel, K. \& Bonfils, C. Identifying external influences on global precipitation. Proc. Natl. Acad. Sci. www.pnas.org/cgi/DOI/10.1073/pnas.1314382110 (2013).

48. Scheff, J \& Frierson, D. Twenty-First-Century Multimodel Subtropical Precipitation Declines Are Mostly Midlatitude Shifts. J. Clim., 25, 4330-4347

49. Levy, A.A.L. et al. Correcting feature location in GCMs aids the detectability of

50. Corti, S., Molteni, F. \& Palmer, T.N., Signature of recent climate change in frequencies of natural atmospheric circulation regimes, Nature, 398, 799-802, (1999).

51. Mann, M.E., Bradley, R.S. \& Hughes, M.K., Long-term variability in the ENSO and associated teleconnections, in ENSO: Multiscale Variability and Global and Regional Impacts, edited by H.F. Diaz and V. Markgraf, pp. 357-412, Cambridge Univ. Press, New York. (2000).

52. Black, E. The influence of the North Atlantic Oscillation and European circulation regimes on the daily to interannual variability of winter precipitation in Israel. International Jn. of Clim., DOI: 10.1002/joc.2383 (2011). 
53. Christensen, J.H. et al. Climate Phenomena and their Relevance for Future Regional Climate Change. In: Climate Change 2013: The Physical Science Basis. Contribution of Working Group I to the Fifth Assessment Report of the Intergovernmental Panel on Climate Change (Stocker, T.F. et al. (eds.)]. Cambridge University Press. (2013).

54. Lavers, D.A. et al. The detection of atmospheric rivers in atmospheric reanalyses and their links to British winter floods and the large-scale climatic circulation. $J$. Geophys. Res. 117, D20106, DOI: 10.1029/2012JD018027 (2012).

55. Lavers, D.A. et al. Future changes in atmospheric rivers and their implications for winter flooding in Britain. Environ. Res. Lett. 8, 034010, DOI:10.1088/17489326/8/3/034010 (2013).

56. Dean, S.M., Rosier, S., Carey-Smith, T. \& Stott, P.A. The role of climate change in the two-day extreme rainfall in Golden Bay, New Zealand, December. [In "Explaining Extreme Events of 2012 from a Climate Perspective"]. Bull. Amer. Meteorol. Soc. 94 (9), S61-S63, DOI:10.1175/BAMS-D-13-00212.1 (2013).

57. Polson, D., Hegerl, G.C., Allan, R.P. \& Balan Sarojini, B. Have greenhouse gases intensified the contrast between wet and dry regions? Geophys. Res. Lett. 40, DOI:10.1002/grl.50923 (2013b).

58. Liu, C. \& Allan, R.P. Observed and simulated precipitation responses in wet and dry regions 1850-2100. Environ. Res. Lett. 8, 034002, DOI:10.1088/17489326/8/3/034002 (2013).

59. Allan, R.P. Climate Change: Dichotomy of drought and deluge. Nature Geosci. DOI: 10.1038/ngeo2243 (2014). 
60. Shepherd, T.G. Atmospheric circulation as a source of uncertainty in climate change projections. Nature Geoscience. DOI: 10.1038/ngeo2253, (2014).

61. Rotstayn, L.D., \& Lohmann, U. Tropical rainfall trends and the indirect aerosol effect. J. Clim., 15, 2103-2116 (2002).

62. Hegerl, G.C. et al. Understanding and Attributing Climate Change. In: Climate Change 2007: The Physical Science Basis. Contribution of Working Group I to the Fourth Assessment Report of the Intergovernmental Panel on Climate Change (Solomon, S. et al. (eds.). Cambridge University Press. (2007).

603

63. Dong, B., Sutton, R., Highwood, E.J. \& Wilcox, L.J. The impacts of European 604 605 and Asian anthropogenic sulphur dioxide emissions on Sahel rainfall. J. Clim., 27, 7000-7017 (2014).

64. Dong, B.-W. \& Sutton, R., Dominant role of greenhouse gas forcing in the 607

608 recovery of Sahel rainfall. Nature Clim. Change. DOI: 10.1038/nclimate2664 (2015).

65. Allen, M.R. Liability for climate change. Nature 421, 891-892 (2003).

66. Stott, P.A., Stone, D.A., \& Allen, M.R. Human contribution to the European heat wave of 2003. Nature, 432, 610-614 (2004).

67. Pall, P., et al., Anthropogenic greenhouse gas contribution to UK autumn flood risk. Nature, 470, 382-385 (2011).

614 68. Herring, S.C., Hoerling, M.P., Kossin, J.P., Peterson, T.C. \& Stott, P.A., Eds., 615 Explaining Extreme Events of 2014 from a Climate Perspective. Bull. Amer. Meteor. Soc., 96 (12), S1-S172 (2015).

617 69. Herring, S., et al. Summary and Broader context [in "Explaining Extremes of 6182013 from a Climate Perspective"]. Bull. Amer. Meteor. Soc., 82 (9) (2014b). 
619 70. Hoerling, M., et al. Northeast Colorado extreme rains interpreted in a climate 620 change context [in "Explaining Extremes of 2013 from a Climate Perspective"]. 621 Bull. Amer. Meteor. Soc., 95 (9), S15-S18 (2014).

622 71. Christidis, N.C. \& Stott, P.A. Extreme rainfall in the United Kingdom during 623 winger 2013/14: the role of atmospheric circulation and climate change [in 624 "Explaining Extremes of 2014 from a Climate Perspective"]. Bull. Amer. Meteor. 625 Soc., 96 (12), S46-S50 (2015).

72. Schaller, N., et al., Human influence on climate in the 2014 Southern England winter floods and their impacts. Nature Clim. Change. (2016).

73. Trenberth et al. Attribution of climate extreme events. Nature Clim. Change. DOI: 10.1038/NCLIMATE2657 (2015).

74. Huntingford C., et al. Potential influences in the United Kingdom's floods of winter 2013-2014. Nature Clim. Change, 4, 769-777 (2014).

75. Stott, P.A., et al., Attribution of extreme weather and climate-related events. WIREs Clim. Change, 7, 23-41. DOI: 10.1002/wcc.380 (2016).

634 76. Power et al. Robust twenty-first-century projections of El Nino and related 635 precipitation variability. Nature. 502, 541-545 (2013).

77. Hegerl, G.C. et al. Good practice guidance paper on detection and attribution 637 related to anthropogenic climate change. In: Meeting Report of the Intergovernmental Panel on Climate Change Expert Meeting on Detection and Attribution of Anthropogenic Climate Change (eds Stocker, T.F. et al.). IPCC Working Group I Technical Support Unit. (2010).

78. Hegerl, G.C. \& Zwiers, F.W. Use of models in detection and attribution of climate change. WIREs Clim. Change, 2, 570-591 (2011). 
79. Harris, I. et al. Updated high-resolution grids of monthly climatic observations the CRU TS 3.1 Dataset. International Jn. of Clim. 34, 623-642 (2014).

80. Becker, A. et al. A description of the global land-surface precipitation data products of the Global Precipitation Climatology Centre with sample applications including centennial (trend) analysis from 1901-present. Earth Syst. Sci. Data Discuss., 5, 971-998. DOI: 10.5194/essd-5-71-2013 (2013).

81. Beck, C., Grieser, J., \& Rudolf, B. A new monthly precipitation climatology for the global land areas for the period 1951 to 2000, Climate Status Report, 181-190 (2004).

\section{Acknowledgements}

This work is supported by Horyuji PAGODA project of the Changing Water Cycle programme of UK Natural Environment Research Council (NERC) (Grant NE/I006672/1) and by the Joint DECC/Defra Met Office Hadley Centre Climate Programme (GA01101). B.B.S. acknowledges joint support from the UK NERC (NE/I006672/1) and the Met Office Hadley Centre, and a discussion with Pier Luigi Vidale and Anne Verhoef on the atmospheric-land surface processes. E.B. was supported by the National Centre for Atmospheric Science - Climate division core research programme and the following research grants: HyCristal (NE/M020371/1), SatWIN-Scale (NE/M008797/1) and BRAVE (NE/M008983/1). The authors are thankful to three anonymous reviewers for their constructive and critical comments on the manuscript.

\section{Author Contributions}

B.B.S. developed the content and led the writing; P.A.S and E.B. designed the outline of the article, contributed to discussions, text, and commented on the drafts.

\section{Competing Financial Interests statement}


668 The authors declare no competing financial interests.

669 Corresponding Author

670 Correspondence to: Beena Balan Sarojini.

$671 \quad$ Figure Legends

672 Figure 1| Observational uncertainties due to sparse coverage obscure expected

673 fingerprints of change: Time-series of global mean precipitation anomalies 674 (mm/day) w.r.t the baseline period of 1961-90, simulated by CMIP5 models forced 675 with, both anthropogenic and natural forcings (ALL in orangish red lines) and natural 676 forcings only (NAT in blue lines). a) Land and Ocean, b) Land, and c) Ocean, with all 677 grid points. Multi-model means are shown in thick solid lines. Green stars show 678 statistically significant changes at $5 \%$ level. The clear signals seen in simulations 679 (above) are obscured by sparse observational coverage when the global land 680 precipitation is masked by observational coverage (Ref. 2).

681 Figure 2| Magnitudes of zonal mean land precipitation trends are dependent on 682 observational datasets: Comparison of observed trends (solid lines) using 4 683 observational datasets (Refs. 11, 79, 80, 81) for 1951-2005 (top). Range of CMIP5 684 simulations are in grey shading and multi-model ensemble mean (MM) in black 685 dashed line. Blue (orange) shadings show latitudes where all observed datasets show 686 positive (negative) trends. Comparison of simulated trends (bottom) using CMIP5 687 historical (ALL) simulations (individual simulations in grey dashed lines, multi-model 688 mean in black dashed line), and the natural forcing only (NAT) simulations (MM in 689 blue dashed lines) with the future (2006-2050) trend using RCP4.5 simulations (5-95 $690 \%$ range is in green shading, and MM in green dashed lines). Blue (orange) shading 691 indicates latitudinal regions where more than two thirds of the historical simulations 692 show positive (negative) trends (Ref. 4). 
694 precipitation change: Zonal mean boreal winter precipitation observations for 1990

695 (left). Local extrema are marked in dark blue (midlatitude storm tracks), red

696 (subtropical dry zones), and green (equatorial tropical peak). Cyan, purple, and yellow 697 circles indicate half-max points. Multivariate fingerprint $F_{m}(D, T)$ of forced 698 precipitation change as thermodynamic (T) and dynamic (D) process indicators 699 (right). Thermodynamic EOF loading is plotted on the vertical axis and the direction 700 and magnitude of dynamic EOF loading are displayed as arrows showing the wet701 gets-wetter and dry-gets-drier pattern in precipitation intensity and the poleward 702 extension of precipitation over storm track and subtropical arid latitudes in both 703 hemispheres (Ref. 47).

704 


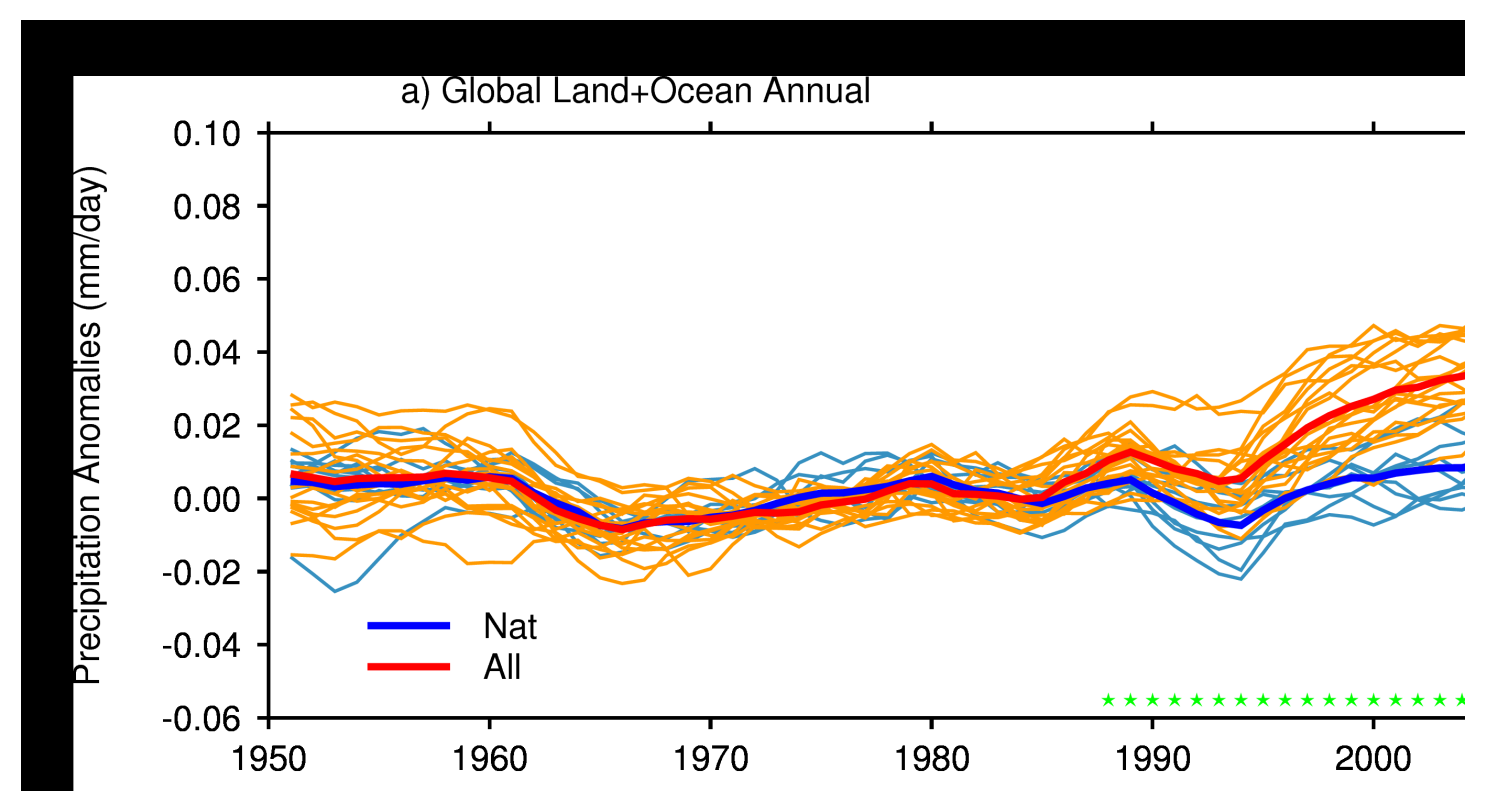

b) Global Land Annual

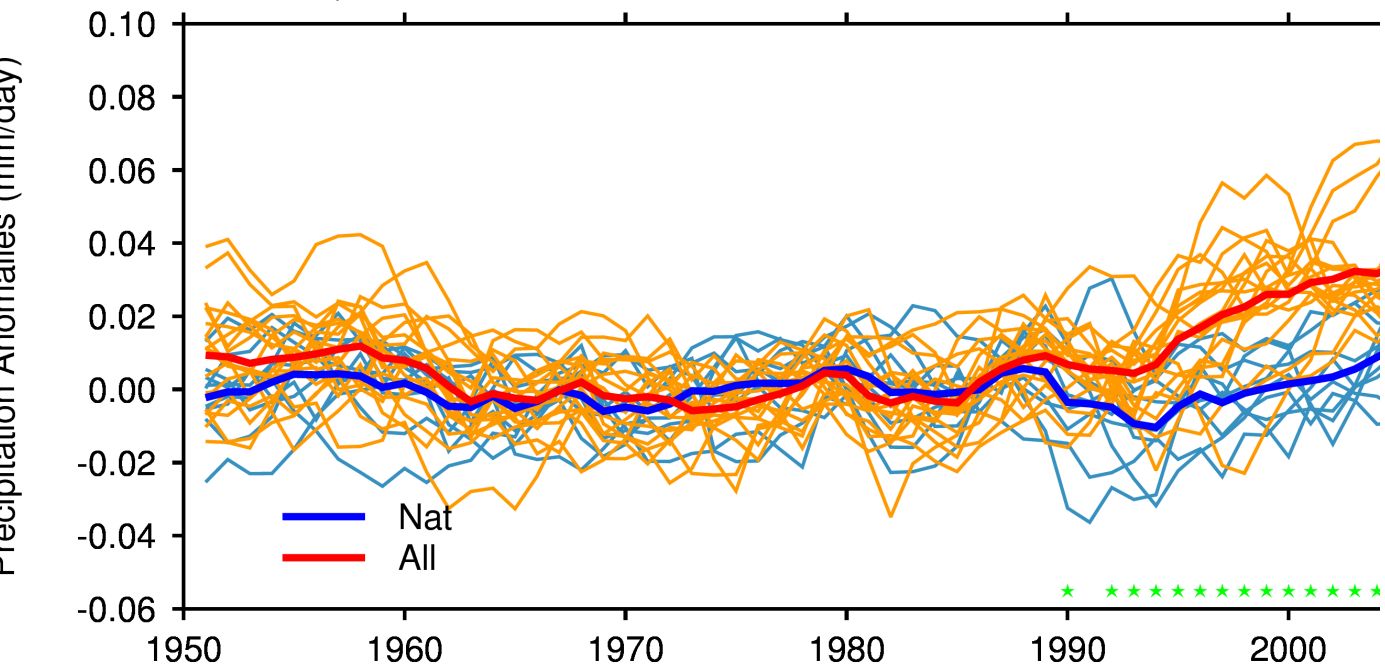

c) Global Ocean Annual

Figure 1| Observational uncertainties due to sparse coverage obscure expected

709 fingerprints of change: Time-series of global mean precipitation anomalies 
710 (mm/day) w.r.t the baseline period of 1961-90, simulated by CMIP5 models forced

711 with, both anthropogenic and natural forcings (ALL in orangish red lines) and natural

712 forcings only (NAT in blue lines). a) Land and Ocean, b) Land, and c) Ocean, with all

713 grid points. Multi-model means are shown in thick solid lines. Green stars show

714 statistically significant changes at $5 \%$ level. The clear signals seen in simulations

715 (above) are obscured by sparse observational coverage when the global land

716 precipitation is masked by observational coverage (Ref. 2).

717

718

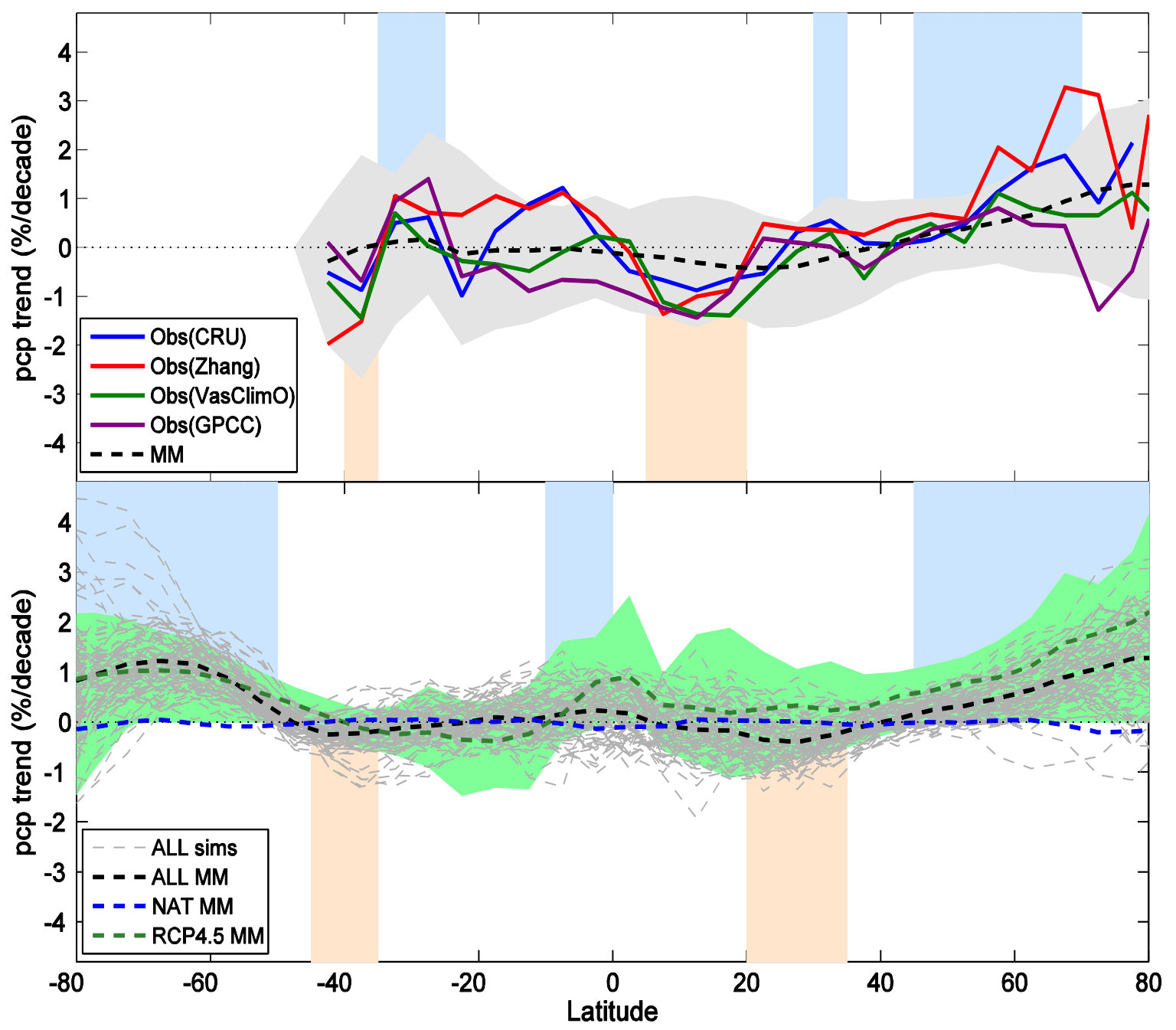


observational datasets: Comparison of observed trends (solid lines) using 4 observational datasets (Refs. 11, 79, 80, 81) for 1951-2005 (top). Range of CMIP5 simulations are in grey shading and multi-model ensemble mean (MM) in black dashed line. Blue (orange) shadings show latitudes where all observed datasets show positive (negative) trends. Comparison of simulated trends (bottom) using CMIP5 historical (ALL) simulations (individual simulations in grey dashed lines, multi-model mean in black dashed line), and the natural forcing only (NAT) simulations (MM in blue dashed lines) with the future (2006-2050) trend using RCP4.5 simulations (5-95 $\%$ range is in green shading, and MM in green dashed lines). Blue (orange) shading indicates latitudinal regions where more than two thirds of the historical simulations 731 show positive (negative) trends (Ref. 4).
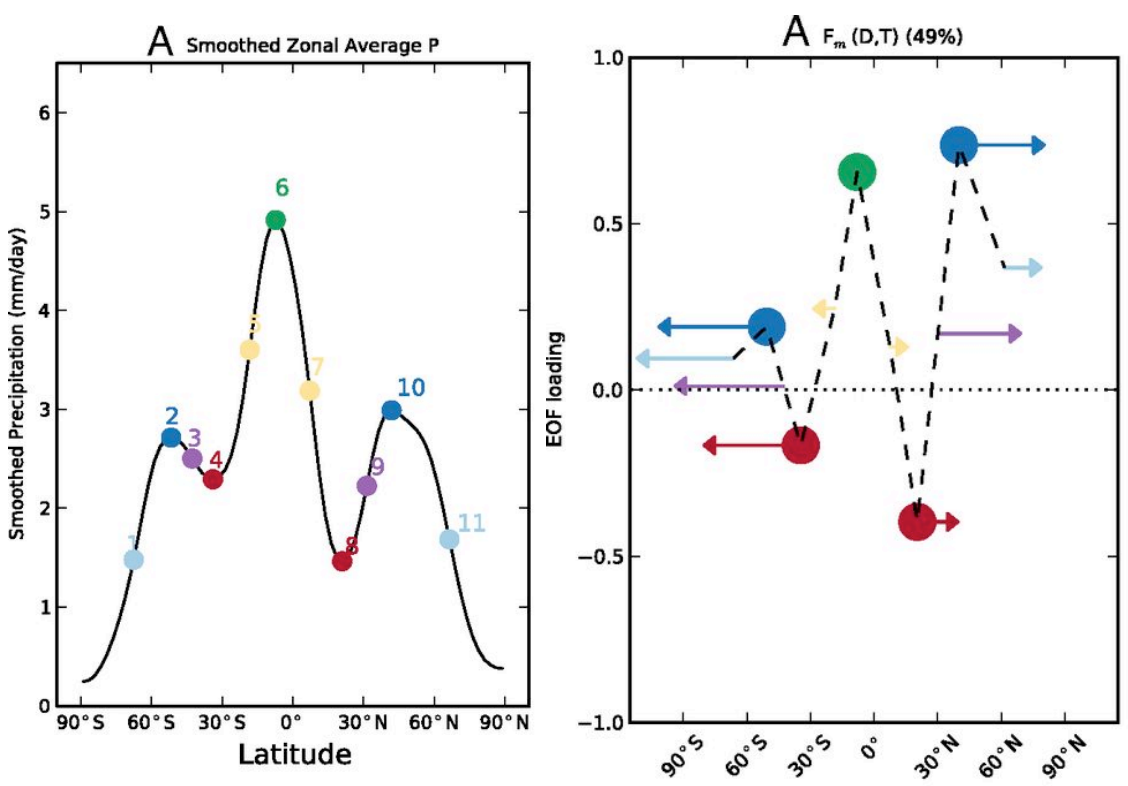

Figure 3| An example of simulated process-based fingerprint of anthropogenic precipitation change: Zonal mean boreal winter precipitation observations for 1990 (left). Local extrema are marked in dark blue (midlatitude storm tracks), red (subtropical dry zones), and green (equatorial tropical peak). Cyan, purple, and yellow 
739 circles indicate half-max points. Multivariate fingerprint $F_{m}(D, T)$ of forced 740 precipitation change as thermodynamic (T) and dynamic (D) process indicators 741 (right). Thermodynamic EOF loading is plotted on the vertical axis and the direction 742 and magnitude of dynamic EOF loading are displayed as arrows showing the wet743 gets-wetter and dry-gets-drier pattern in precipitation intensity and the poleward 744 extension of precipitation over storm track and subtropical arid latitudes in both 745 hemispheres (Ref. 47).

746

747 